\title{
Applications of Natural, Semi-Synthetic, and Synthetic Polymers in Cosmetic Formulations
}

\author{
Thais F. R. Alves ${ }^{1}\left(\mathbb{D}\right.$, Margreet Morsink ${ }^{2,3,4}{ }^{\oplus}$, Fernando Batain ${ }^{1}$, Marco V. Chaud ${ }^{1}{ }^{\circledR}$, \\ Taline Almeida ${ }^{5,6}$, Dayane A. Fernandes ${ }^{7,8}$, Classius F. da Silva ${ }^{7}$ (D) Eliana B. Souto ${ }^{9,10, *(\mathbb{D})}$ \\ and Patricia Severino $2,5,6,11, *$ (D) \\ 1 Laboratory of Biomaterials and Nanotechnology, University of Sorocaba-UNISO, Sorocaba, \\ 18023-000 São Paulo, Brazil; thaisfrancine1@hotmail.com (T.F.R.A.); fbatain@gmail.com (F.B.); \\ marco.chaud@prof.uniso.br (M.V.C.) \\ 2 Center for Biomedical Engineering, Department of Medicine, Brigham and Women\& Hospital, Harvard \\ Medical School, 65 Landsdowne Street, Cambridge, MA 02139, USA; m.a.j.morsink@student.utwente.nl \\ 3 Translational Liver Research, Department of Medical Cell BioPhysics, Technical Medical Centre, \\ Faculty of Science and Technology, University of Twente, 7522 NB Enschede, The Netherlands \\ 4 Department of Developmental BioEngineering, Faculty of Science and Technology, Technical Medical Centre, \\ University of Twente, 7522 NB Enschede, The Netherlands \\ 5 University of Tiradentes (Unit), Biotechnological Postgraduate Program. Av. Murilo Dantas, 300, \\ 49010-390 Aracaju, Brazil; talinealmeida2009@hotmail.com \\ 6 Institute of Technology and Research (ITP), Nanomedicine and Nanotechnology Laboratory (LNMed), Av. \\ Murilo Dantas, 300, 49010-390 Aracaju, Brazil \\ 7 Department of Chemical Engineering, Laboratory of Biotechnology and Natural Products, \\ Federal University of São Paulo, 09913-030 Diadema, São Paulo, Brazil; dayane.qui@gmail.com (D.A.F.); \\ classiusferreira@yahoo.com.br (C.F.d.S.) \\ 8 Research and Development (R\&D), Stepan Química Ltd.a, Vila Mariana,04019-030 São Paulo, Brazil \\ 9 Department of Pharmaceutical Technology, Faculty of Pharmacy, University of Coimbra, \\ Pólo das Ciências da Saúde, Azinhaga de Santa Comba, 3000-548 Coimbra, Portugal \\ 10 CEB-Centre of Biological Engineering, University of Minho, Campus de Gualtar, 4710-057 Braga, Portugal \\ 11 Tiradentes Institute, 150 Mt Vernon St, Dorchester, MA 02125, USA \\ * Correspondence: ebsouto@ff.uc.pt (E.B.S.); patricia_severino@itp.org.br (P.S.)
}

Received: 17 July 2020; Accepted: 23 September 2020; Published: 25 September 2020

\begin{abstract}
Cosmetics composed of synthetic and/or semi-synthetic polymers, associated or not with natural polymers, exhibit a dashing design, with thermal and chemo-sensitive properties. Cosmetic polymers are also used for the preparation of nanoparticles for the delivery of, e.g., fragrances, with the purpose to modify their release profile and also reducing the risk of evaporation. Besides, other cosmetically active nutrients, dermal permeation enhancers, have also been loaded into nanoparticles to improve their bioactivities on the skin. The use of natural polymers in cosmetic formulations is of particular relevance because of their biocompatible, safe, and eco-friendly character. These formulations are highly attractive and marketable to consumers, and are suitable for a plethora of applications, including make-up, skin, and hair care, and as modifiers and stabilizers. In this review, natural synthetic, semi-synthetic, and synthetic polymers are discussed considering their properties for cosmetic applications. Their uses in conventional and novel formulations are also presented.
\end{abstract}

Keywords: cosmetic; dashing design; polymers; co-polymers; polysaccharides 


\section{Introduction}

In the 21st century, cosmetic and personal care industries have been increasing rapidly. The global cosmetics market is projected to register a compound annual growth rate of $4.3 \%$ during the forecast period (2016-2022) and is anticipated to reach $\$ 429.8$ billion by 2022 [1].

The European Commission (2015) has defined cosmetics as any substance or preparation intended to be placed in contact with the various external parts of the human body (epidermis, lips, external genital organs, hair system, and nails), teeth, and the mucous membranes of the oral cavity [2]. Indeed, polymers are found in hair products, such as shampoo, conditioner, tip repair, hair dye, moisturizing masks, and fixing gels; in skincare products, such as liquid soaps, moisturizing lotions, sunscreen, and corporate oils; as well as products used in nail care, make-up, and fragrance [3]. Each of these products has distinct functions and applicability, in addition to different characteristics in the composition, manufacturing process, and physical and chemical parameters that demand a great diversity of polymers.

Polymers are an important class of raw materials of cosmetic formulations, being essential in the production of high-performance products. They are classified as synthetic, semi-synthetic, or natural (Figure 1) macromolecules composed of many repeating units (monomers) usually arranged in the form of a chain. In cosmetics formulations, its structural diversity is used to promote a variety of functions as rheology modifiers, thickeners, foam stabilizers and destabilizers, emulsifiers, fixatives, conditioning, and film formers [3-5].

In this review, we discuss the properties and uses of natural, semi-synthetic, and synthetic polymers in cosmetic formulations.



Figure 1. Main types of polymers natural, semi-synthetic, and synthetic polymers applied in cosmetics.

\section{Methodology and Data Analysis}

An overview of the publications about polymers applied in cosmetics was carried out from a search for publications in the Web of Science database by Clarivate Analytics. This search was limited to the last 20 years (from 2000 to 2019), and considering only original works. Initially, we searched for the word "cosmetics" in the title of the papers to ensure that only cosmetics-driven works were considered. The term "cosmetics" was found in 4485 papers. The results were then refined by directly searching for different polymers, i.e., each polymer name was searched in these 4485 articles, not only in the title but in any search field. The "**" was used as a wildcard to find inflections and distinct ways of referring to the same polymer.

The results are presented in Figure 2, resulting in three distinct groups of polymers classified as: Natural polymers (plant or animal origins), semi-synthetic polymers (chemically modified natural 
polymers-from plant or animal origins), and synthetic polymers (fermentation or chemical routes). All the polymers (natural, semi-synthetic, and synthetic) were found in 219 papers.

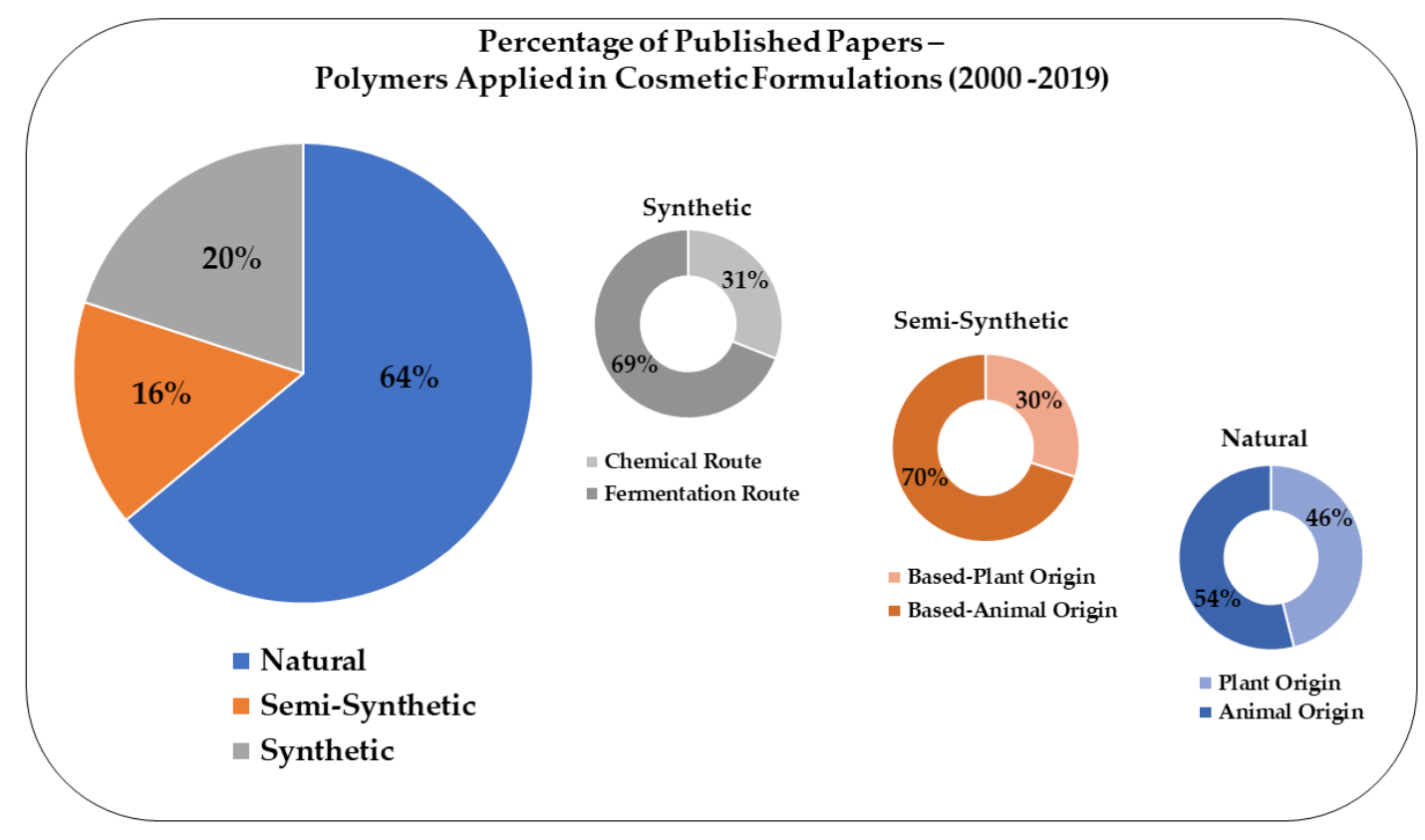

Figure 2. Results of an overview of original publications about polymers applied in cosmetic formulations (source: Web of Science database by Clarivate Analytics).

\section{Polymers Applied in Cosmetic Formulations}

Polymers have been routinely used in much personal care and cosmetic products. They represent one class of materials with a range of properties as diverse as the class of polymers that have been utilized. This section approaches the class of polymers that have been used in a range of applications. Table 1 shows some types of synthetic, semi-synthetic, and natural polymers and their properties in cosmetics formulations.

\subsection{Synthetic Polymers}

Synthetic polymers are attractive as an excipient for cosmetics formulation as they can be tailored for specific applications. They are often cheaper than natural polymers, can be produced on a large scale with uniformity, and have a long shelf time. The synthetic polymers most commonly found in cosmetics are acrylic acid-based polymers, polyacrylamides, silicon, and alkylene oxide-based homopolymers and copolymers [6].

Table 1. Functional properties of polymers applied to cosmetics.

\begin{tabular}{|c|c|c|}
\hline Polymer & Properties & Ref. \\
\hline \multicolumn{3}{|c|}{ Synthetic } \\
\hline PEG/PPG & Surface activity, humectant, & [7] \\
\hline Dimethicone & $\begin{array}{l}\text { emollience, enhanced comfort, and protection } \\
\text { Thermoreversible hydrogels, }\end{array}$ & \\
\hline Poloxamer & $\begin{array}{c}\text { increase the viscosity in body temperature, } \\
\text { surfactant non-ionic }\end{array}$ & [8] \\
\hline $\begin{array}{l}\text { Poly (lactic acid), } \\
\text { Poly ( } \varepsilon \text {-caprolactone })\end{array}$ & $\begin{array}{l}\text { Exfoliants microbeads, biodegradable-alternative to } \\
\text { non-biodegradable polymers (e.g., polyethylene) }\end{array}$ & [9] \\
\hline Polyurethanes & $\begin{array}{l}\text { Film formation, elastic properties, shape memory effects, } \\
\text { surface feel, gloss, and water resistance }\end{array}$ & [10] \\
\hline Polyquaternarium & Conditioning, antistatic and film-forming & [11] \\
\hline
\end{tabular}


Table 1. Cont.

\begin{tabular}{|c|c|c|}
\hline Polymer & Properties & Ref. \\
\hline \multicolumn{3}{|c|}{ Semi-Synthetic } \\
\hline \multirow{3}{*}{$\begin{array}{c}\text { Nitrocellulose, } \\
\text { Acrylate-copolymers } \\
\text { Hydroxypropyl methylcellulose, } \\
\text { Hydroxyethyl cellulose, } \\
\text { Polyacrylic-acid, } \\
\text { Polyamides }\end{array}$} & $\begin{array}{l}\text { Film formation, extended product wear, enhanced skin } \\
\text { protection, improved product aesthetics }\end{array}$ & [12] \\
\hline & $\begin{array}{l}\text { Rheological control, ease of application and enhanced } \\
\text { product shelf life }\end{array}$ & [7] \\
\hline & Natural & \\
\hline Starch & Emulsifying ability, film formation, high viscosity & [13] \\
\hline Chitosan & $\begin{array}{l}\text { Moisturizing elastic film, active lip care ingredient, } \\
\text { hydration, long-term color adhesion, antimicrobial } \\
\text { properties, and fragrance adhesion }\end{array}$ & [14] \\
\hline Cellulose & $\begin{array}{l}\text { Rheological control, film formation, } \\
\text { leaves the hair soft and smooth, well-hydrated, and is } \\
\text { anti-static }\end{array}$ & [15] \\
\hline Sericin & $\begin{array}{l}\text { Improves elasticity, large capacity } \\
\text { to absorb water, and moisturizes }\end{array}$ & {$[16,17]$} \\
\hline Collagen & $\begin{array}{c}\text { Antioxidant properties, antihypertensive activity, } \\
\text { lipid-lowering activity, as well as reparative properties in } \\
\text { damaged skin }\end{array}$ & [18] \\
\hline Hyaluronic acid & $\begin{array}{c}\text { Skin conditioning agents, moisturizing, skin protective, and } \\
\text { anti-aging properties }\end{array}$ & [19] \\
\hline $\begin{array}{c}\text { Ulvan } \\
\text { Carrageenan }\end{array}$ & $\begin{array}{l}\text { Gelling properties, but it is affected by boric acid, divalent } \\
\text { cations, and } \mathrm{pH}\end{array}$ & [20-22] \\
\hline
\end{tabular}

Over the last years, silicon materials have been used in the cosmetics industry. Silicon and its composites (e.g., biomethane and cyclomethycaine) are used in cosmetics, such as deodorants, shampoos, antiperspirants, and lotions as suspending agents and processes, such as emulsification and associative thickening [4].

Polyethylene glycols (PEGs), and their anionic or non-ionic derivatives, are widely used in cosmetics as emollients (which help with softening and lubricating of the skin), as emulsifiers (which help water-based and oil-based ingredients to mix properly), and as penetration enhancers that help the delivery of other ingredients deeper into the skin. They are used in bath products, shaving products, skin care products, make-up, skin cleansing products, shampoo, hair conditioners, and deodorant [23]. Poomanee et al. (2020) developed nanoemulsion loadings with Mangifera indica L. kernel extract to enhance the stability and skin permeation of the extract to be a promising anti-acne product [24]. The mixture was composed of safflower oil as the oil phase, PEG-7 glyceryl cocoate, the surfactant mixture of Ceteareth-20, PEG-40 hydrogenated castor oil, and sorbitan oleate along with butylated hydroxytoluene. A nanoemulsion with very small droplet sizes and a narrow distribution, was obtained, depicting the physicochemical and antibacterial stability, as well as the skin permeability, of $M$. indica kernel extract.

Aliphatic polyesters, such as poly (lactic acid) (PLA), poly ( $\varepsilon$ caprolactone) (PCL), and poly(3-hydroxybutyrate-co-3 hydroxy valerate), have excellent properties of biodegradability, biocompatibility, and mass producibility. These materials have melted processability and excellent mechanical properties, properties that are not found in natural polymers (such as in cellulose, chitin, and gelatin). Due to their properties, aliphatic polyesters are receiving attention for the production of microbeads for sustainable cosmetics [9].

\subsection{Semi-Synthetic Polymers}

Cellulose ethers and cellulose esters are two main groups of cellulose derivatives with different physicochemical and mechanical properties. Cellulose derivatives have properties, such as viscosity in solution, surface activity, thermoplastic film characteristics, and stability against biodegradation, heat, hydrolysis, and oxidation. The cellulose ethers (e.g., methylcellulose, ethyl cellulose, hydroxyethyl 
cellulose, hydroxypropyl methylcellulose, carboxymethyl cellulose, and sodium carboxymethyl cellulose) are water-soluble, unlike cellulose esters (cellulose acetate, cellulose acetate phthalate, cellulose acetate butyrate, cellulose acetate trimelitate, hydroxypropyl methylcellulose phthalate), which are generally water-insoluble polymers but with good film-forming characteristics [25]. These polymers are mostly used as gelling agents, bioadhesive, thickening, and stabilizing agents applied in cosmetics like creams, shampoos, lotions, and gels. They are less sensitive against microbial contamination than natural gelling agents, such as starches, acacia, sodium alginate, agar, pectin, and gelatin [7].

Aung et al. (2019) developed dissolving microneedles using polymer synthetic, semi-synthetic, and natural polymers, or a mix of polymers to promote transepidermal delivery of alpha-arbutin for skin lightening [26]. The polymers used to prepare the patch were Gantrez ${ }^{\mathrm{TM}}$ S-97, hydroxypropyl methylcellulose, polyvinylpyrrolidone K-90, and chitosan. They observed that 8\% w/w HPMC:40\% $\mathrm{w} / \mathrm{w}$ PVP K-90 (1:1) is the mix of the most suitable polymer to fabricate alpha-arbutin-loaded dissolving microneedles due to the better mechanical strength and penetration of alpha-arbutin than the gel formulation.

\subsection{Natural Polymers}

Natural polymers have been mostly used for cosmetic applications, as depicted in Figure 2. They are biocompatible, safe, eco-friendly, highly marketable to consumers, and are suitable for a plethora of applications, including make-up, skin and hair care, and as modifiers and stabilizers [27,28]. Among the most commonly used natural polymers, polysaccharides, starch, xanthan gum, guar gum, carrageenan, alginate, pectin, gelatine, agar, collagen, and hyaluronic acid are of special relevance.

Starches are naturally occurring polysaccharides, which can be used in different forms, namely as soluble starch and as a granule starch. The soluble starch is heated upon extraction, and it becomes humidity resistant upon drying, resulting in smooth hair and skin. The granule starch has its hydrogen bonds modified, so that it is unbreakable, which results in soft, moisturized, and reduced greasiness of the hair and skin [13]. The various sources of starch like non-ionic polymers, including potato, corn, pinion [29], and cassava root, all give slightly different properties to the cosmetic formulations, as a result of their different amylose contents. The combination of starch with other natural polymers like chitosan to antioxidative release, and other activities compounded to the skin have been used [30].

Chitosan is often used on its own in cosmetic applications as well, for instance, for hair and skin care, as well as in lotions and nail lacquers. It is a highly potent moisturizing agent, and is also used to moisturize the skin and lips. Moreover, it can be used to provide sunscreens with water-resistant properties. Chitosan is also widely known for its antimicrobial properties [31-33], and is therefore used in various deodorants, especially since the solution remains sprayable [14]. Chitosan improves fragrance adhesion, and is also used as a stabilizer in various formulations [34-37], enabling skin adherence [38]. Additionally, chitosan can be used to treat acne [39]. The moisturizing ability of chitosan comes from its high molecular weight and positive electrical charge, aesthetics appeal, and comfort of textile-based transdermal therapy [40,41]. Chitosan has also been used as a vehicle for therapeutic products with different activities, for instance, chitosan gels containing herbal extracts showed a dental plaque reduction of $70 \%$ and a reduction of bacterial counting of $85 \%$. Chitosan microparticles containing sodium fluoride were produced by spray-drying to work in the oral cavity as a fluoride reservoir for fluoride-controlled delivery systems. Dental varnishes containing chitosan nanoparticles as a fluoride-controlled delivery system carrier were developed with antimicrobial activity against $S$. mutants and the ability to inhibit demineralization was confirmed [42-45].

Cellulose is another naturally occurring polymer; however, it is insoluble in water and can therefore not be used in cosmetic applications in its natural form; it requires chemical modifications, such as substitution reactions. Upon chemical modification, cellulose fibrils create non-irritant skin products with good spreadability and adherence to the skin, being ideal to use as a face mask [46]. Moreover, ionic cellulose polymers are used as a thickener to increase the viscosity and stability of specific cosmetical formulations. One cationic hydroxyethyl cellulose polymer, named polyquaternium-10, is 
widely used in hair conditioning products, as it is anti-static and moisturizing, and leaves the hair smooth and shiny [15].

Cellulose can be combined with other natural polymers for cosmetic applications, such as carrageenan, and used as a thickener [22]. Carrageenan can act as a binder on its own, increasing the adhesion and viscosity of formulations [47]. Modified celluloses have been used for numerous applications by the cosmetic industries, mainly as rheology modifiers and colloidal stabilizers. Modified celluloses are large molecules, so their adsorption process is much slower than small molecules as surface-active agents. In proper conditions, the modified starch and cellulose together with galactomannan, alginates, hyaluronan, and ulvan may provide superior stability against aggregation due to an interfacial display, steric repulsion, and entropic contributions for oil/water and water/oil emulsions arising from thick stabilizing layers [48].

Silk fibroin and silk sericin are classified as Mulberry silk (collected from Bombyx mori) and non-Mulberry silk (collected from sources other than Bombyx mori). Whilst Mulberry silk has superior biocompatibility and biodegradable properties when compared to synthetic protologues, it promotes less inflammation than other biopolymers [49]. Silk fibroin can be used in creams and shampoos, as it increases elasticity and moisturizes. It has also been used in products to prevent brittleness of nails. Silk fibroin microparticles have high crystallinity, and low sphericity indexes. The high crystallinity index offers higher physicochemical stability, therefore facilitating processing for cosmetical purposes. Structurally, the silk fibroin is characterized by repetitive hydrophobic and hydrophilic peptide sequences and consists of heavy- and light-chain polypeptides, linked by a disulphide bond at the C-terminus. The fabrication of silk fibroin microparticles is carried out using aqueous silk fibroin solution under mild temperatures, for further use to encapsulate temperature-sensitive bioactives [50,51].

The 3-D structure of fibroin protein arranged as a beta-pleated sheet structure induces gelation, and can be considered as a stability-hampering factor as freighting of the finished product. However, silk protein has unlimited scope for cosmetic release at a controlled rate from micro and nanoparticulate structures. The applicability of sericin is a result of the high content of amino acids with hydrophilic side groups in its structure, which enhances its ability to absorb water and provide hydration to the hair and skin $[16,17]$. Alginate microspheres containing silk sericin were prepared using electros-praying and showed controlled drug delivery with high encapsulation efficiency. Silk fibroin protein-blended calcium alginate beads resulted in prolonged cosmetic release without an initial burst, when compared to calcium alginate beads without silk fibroin [52,53].

Collagen is a prevalent component of the extracellular matrix (ECM), and it has been used in anti-aging and anti-wrinkling products. It is used in the development of cosmetic formulations as a moisturizer and natural humectant to the skin [18]. Collagen can be mainly extracted from bovine and porcine by-products; however, other sources, such as marine collagen (marine sponges, jellyfish, squid, and fishes), are arising as a relevant alternative to their mammalian counterparts [54,55].

Alves et al. (2017) isolated collagen from salmon and codfish skins to evaluate its moisture uptake capability and its irritant potential, with aim to use this marine collagen in cosmetic preparations [54]. The results showed the high purity of the obtained type I collagen but with some structural and chemical differences between salmon and codfish skins. Collagen demonstrated a good capacity to retain water, thus being suitable for dermal applications as a moisturizer. A topical exposure of collagen in a human reconstructed dermis, and analysis of molecular markers for irritation and inflammation does not show irritant potential. Ulvan is a water-soluble sulphated hetero polysaccharide with gelling properties in the presence of divalent cations (Ca2+, $\mathrm{Cu} 2+$, and $\mathrm{Zn} 2+)$, in a $\mathrm{pH}$ range of 7.5 to 8.0, and tolerates temperatures up to $180{ }^{\circ} \mathrm{C}$. The rheological, film formation, and bifunctional properties of ulvan make them desirable as raw material for cosmetics. The physicochemical properties and molecular characteristics show the existence of typical properties and behavior of self-aggregation molecules that are not commonly found in other natural polymers [56,57]. The ulvan stabilizing 
and emulsifying capacity was investigated by Morelli et al. (2019), who obtained a stable colloidal formulation with potential food and cosmetic application [58].

\section{Overview of Polymers Applied to Cosmetics}

Although polymers are strongly responsible for several characteristics and benefits for cosmetics, their performance is directly related to the presence of other components in the formulation, such as the type of solvent, surfactant, and electrolytes, as well as the $\mathrm{pH}$, order of addition of raw materials during product manufacture, and processing conditions, such as the temperature and agitation rate [6]. It is crucial to evaluate the compatibility of the polymer to be used with each of the raw materials that make up the product to avoid the occurrence of phenomena related to formulation instability, such as turbidity and phase separation.

In shampoo formulations, polymers are responsible for promoting a variety of attributes that are associated with the multifunctionality required by the consumer, since in addition to removing excess oil from the hair, it is expected that the shampoo will promote a moderate sensation of softness, shine, resistance to damage, and reduction of split ends. Small dosages of cationic polymers, such as polyquaternium-10 and polyquaternium- 44 , can contribute to the benefits mentioned for the shampoo, since they act in the formation of a film on the hair, in addition to promoting rheological changes and changes in the appearance of the foam [59]. It is worth mentioning that cationic surfactants, which can also deposit forming films on the hair, cannot be used in shampoo formulations because they are incompatible with the anionic surfactants that are present in most shampoos and are responsible for carrying out the removal of excess oil associated with a feeling of cleanliness.

The interaction between anionic and cationic surfactants results in the neutralization of the charges of the molecules producing a water-insoluble compound. Non-ionic polymers, such as guar gum and xanthan gum, will act mainly in the construction of viscosity, not being directly associated with other functions.

In conditioning and moisturizing products, such as conditioners and masks used in hair treatment, where more intense hydration of the hair is necessary, the polymers act by enhancing the sensation of softness promoted by the cationic surfactant, besides helping the improvement in the combability performance, and shine by a film-forming mechanism similar to that described for shampoos.

Cationic and non-ionic polymers can be used in this type of formulation to promote thickening. Another product widely used in hair care is the tip repair oil with a thermal protection function. It is a product suitable for hair that undergoes thermal processes, such as hot flat irons, blows dryers, and curling irons, which can cause damage to the hair due to the combination of a high temperature and friction. Hair is basically made up of proteins that, when subjected to high temperatures $\left(\sim 200^{\circ} \mathrm{C}\right)$, undergo a change in conformation, and degradation in a measurable amount, in addition to the formation of micropores resulting from the disintegration of the cells of the cuticle that result in wire breakage. Zhou et al. (2011) carried out a study to evaluate the performance of some polymers in capillary thermal protection. They concluded that pre-treatment of hair with selected high molecular weight polymers containing film-modifying groups or hydrophobic units, such as VP/acrylates/lauryl methacrylate copolymer, polyethylene carbonate (PEC), and polyquaternium-55, clearly provide thermal protection to the hair, evicting damage [60].

Polymer-based fixing gels are a type of product that acts to preserve the shape of the hairstyle by forming a film on the strands that do not detach when brushing or combing the hair, nor does it confer a sticky feeling. They are products that have an easy application, promote volume, and shine without leaving the feeling of excessive hardness to the thread [61]. These products must be compatible with the moisture of the hair at the moment of application, and, once it is dry, it must be resistant to external moisture so that the formed film remains flexible and does not break, releasing fragments. The most commonly used polymers in the formulation of these products are the copolymers of vinylpyrrolidone and vinyl acetate (PVP/VA), anionic polymers (derived from carboxylic acid), such as copolymers of 
vinyl acetate and crotonic acid, copolymers of methyl vinyl ether and maleic semesters and polyacrylic resins, amphoteric polymers, and dimethylhydantoin-formaldehyde [62].

In hair dyes, polymers are used as emulsifiers [6]. There are also studies reporting the use of polymers to increase the specificity of the pigment to the hair, reducing the unwanted effect of simultaneous skin coloring [63] and polymers associated with pigments, which act in the formation of a colored film on the threads during the hair washing process [64,65].

The polymers used in skincare formulations can have a multitude of functions to meet the vast demand for applications in this segment. As a rheological modifier, the polymers act in a way that favors obtaining a product with adequate viscosity, easy to apply, easy to remove from the packaging, and sensorially pleasant to the touch. Cationic polymers can act in the formation of films on the skin, which promote the sensation of prolonged hydration since they help to reduce water evaporation from the skin. In dermo-cosmetics, the hydroxypropyl methylcellulose (HPMC), Carbopol ${ }^{\circledR}$ 934P, sodium alginate has been used as a vehicle for active molecules in a gel-type administration system [66]. In sunscreen, polymers can act as thickeners and also as emulsifiers, since sunscreens are fat-soluble compounds [67]. Due to the ability to re-emulsify after breaking the emulsion, hydrophobically modified versions of carbomers promote the prolonged effect of the action on sunscreens that use the claim of "resistant to the action of sweat" [13].

In make-up products, polymers are one of the main factors responsible for the "water-resistant", "waterproof", and "long-lasting" effects. These polymers promote the formation of a hydrophobic film on the application area that varies in the degree of hydrophobicity. Water-resistant products are usually intended for use on the skin, such as foundations and blush, where the fixation cannot be exaggerated to allow perspiration. The waterproof products are those that have the most significant fixation on the application surface, as is the case with mascara and eyeliner. Long-lasting products have an intermediate performance, as is the case with lipsticks, where the presence of polymers allows the product to remain for a higher number of hours affixed to the skin, even in the presence of water.

Another cosmetic product in which polymers are the primary raw material is nail polish, which consists of a combination of polymers diluted in volatile solvents. In nail polish, a polymer obtained from the cellulose tri-nitration reaction, is responsible for forming the primary film that promotes strong adhesion to the nail. Tosylamide formaldehyde or toluene-sulphonamide-formaldehyde resins form the secondary film, which gives shine, resistance, and durability to enamels, which are replaced by polyester resins in hypoallergenic nail polish, which provides less resistance compared to previous resins [68].

Fragrances are the invaluable raw materials for the cosmetics industry since the fragrance is the first evaluation criterion used by consumers when choosing a product. The chemistry involved in the production of a fragrance is complex and elaborate, requiring from this raw material a combination of attributes that must meet consumer expectations and be compatible with the formulation in which it will be applied. Many of these fragrances are essential oils [69-72], which are commonly "encapsulated" in, e.g., polymeric delivery systems when a manufacturer wants to use the long-acting claim. This is a desirable attribute for all types of cosmetics containing fragrances, since it brings benefits and as an add value to the product.

Microencapsulation and nanoencapsulation techniques can be used to incorporate fragrances into polymers and thus increase the period of action through a controlled delivery of the active molecules. The fragrance release mechanism can occur in several ways, such as through the breaking of microcapsules by friction, increased temperature, or skin moisture. For this application, different types of polymers are used, which must be compatible with the chemical structure of the fragrance and also with the desired release mechanism [73].

\section{New Trends in Cosmetics}

Chemicals used in cosmetics can interact with another chemical compound present in the dermocosmetic formulations, as well as with body enzymes, resulting in beneficial or detrimental 
effects. Thus, pre-formulation must be carried in order to ensure the compatibility of the selected ingredients to figure in the formulation.

In silico methods, such as molecular modelling and quantitative structure-activity relationship (QSAR) studies, have been performed as a way to anticipate information on physicochemical, toxicological, and biological profiles of the compounds and their interactions [74].

Many different groups of polymers are used in cosmetics to achieve a wide diversity of attributes. The polymeric ingredients are developed not only for technical functions but also for specifics targets where appearance and sensation are both equally important.

Cosmetic flow powders or compacted powders have been used for many decades. Currently, they are used to provide adhesiveness, slipperiness, absorbance, and sleekness, and the efflorescence effect they provide a skin looks healthier, more vital, and youthful. Nowadays, the solid cosmetics dosage forms that matter for keeping the appearance and good conditions of the body are aerated powders in a micro- or nano-sized structures, or as active carriers dispersed in emulsions, gels, and liquid to form a suspension.

Like an adjuvant ingredient, polymeric powders have become standard for the formulation [75], especially in a compacted specialty where they provide a non-sticky touch, cohesion, and a soft after-feel. Like skincare and sun care, powder adjuvant ingredients can improve the emollient effect and enhance the sensory feeling [76].

Cosmetic powders, such as $\mathrm{Mg}_{3} \mathrm{Si}_{4} \mathrm{O}_{10}(\mathrm{OH})_{2}$ powder, are not only used on the feet or baby' skin, but they are also ordinarily added to topical cosmetic formulations to adjust the skin feel during and after product application. Nowadays, a broad diversity of polymeric cosmetic powders are accessible, which differ from each other in features, such as shape, size, compressibility, water, or oil absorption. Recognition of how these properties affect tactile performance would provide a powerful design tool for developers of cosmetic formulations. There is currently considerable interest to develop ways to improve the measurement of tactile perception of powders based on synthetic polymers. However, essential aspects related to the harmful environmental impact has limited the advancement in the use of these polymers [77].

The polymethylsilsesquioxanes (PSA) and polymethylmethacrylate cross-polymer (PMMA) are synthetic polymers. The PSA has a backbone composed of repeating units of siloxane. In contrast, the PPMA has repeating units of methyl methacrylate (one monomer), and methyl methacrylate/glycol dimethacrylate (cross-linking two monomers methyl methacrylate and ethylene dimethacrylate). The PSA is a spherical microparticle resin from four to six microns, which allows it to be easily distributed in powder, suspension, and emulsion formulas. These polymers function as an invisible film on the surface of skin, creating a smooth and silky feel. It still allows change of gas and other important nutrients to pass through but blocks water from evaporating. Additionally, the film formed by PSA has an excellent water-repelling effect. This property has been useful for the formulation of sun protection products. The use of PSA in anti-aging products is due to its ability to temporarily keep the skin moisturized and fill in fine lines, giving the skin a plumper appearance, and decreasing inflammatory phenomena [78-80].

PSA is frequently used in anti-aging skincare products. The PMMA is a biocompatible tiny polymer appearing as an ingredient in a number of cosmetics (eye makeup, other makeup, as well as hair, nail care), aestheticians (soft tissue filler under the skin to reduce, permanently, wrinkles or treat atrophic acne scars, orthodontic appliances, and fabrication of dental prosthetics), and methyl methacrylate cross-polymer may also function as a viscosity-increasing agent, nonaqueous [81-83].

Polyamide (Nylon 6 or Nylon 12 powder), which is chemically neutral, is a dimer-acid, prepared by heating vegetable-derived fatty acids over clay, and is a viscous, lipophilic, and non-crystalline oil. Simple amide bond formation with selected diamines and mono-alcohol or mono-amine terminators yields a diverse range of polyamide products and combines a soft touch with excellent absorption properties and facilitates the application and spreadability. The PA layer is prepared by interfacial polymerization reaction between a polyfunctional amine as $\mathrm{m}$-phenylenediamine, and a polyfunctional 
acyl chloride molecule trimesyol-chloride. These polymers can form shear-thinning oil-based gels. The modulus of the Nylon 12 gel from deformable gel up to a clear hard stick form is proportional to the concentration of polyamide used, and the gelation mechanism is postulated to arise from a supramolecular hydrogen-bonded network [84].

Given the growing demand for high-quality textiles for skincare, much research is focused on the creation of antimicrobial finishing for fabrics to protect customers from pathogenic or odor-generating microorganisms. The coating can be performed by an in situ process in which the nanoparticles are formed and subsequently thrown and twisted onto the surface of Nylon 12 at a very high speed by deposition of metal-oxide or organic nanoparticles of tannic acid and chitosan on the Nylon 12 textiles in killing bacteria, avoiding biofilm formation [81,85-87].

Cutaneous and subcutaneous layers of the skin are the main focus for research in cosmetic compound delivery for protecting the body or keeping it in a healthy condition. Many compounds and drugs have been evaluated for dermal or transdermal effects. However, the stratum corneum, the outermost layer of the skin, is a significant physical barrier to keep the homeostasis, so it is both to transport water out of the body and to allow microorganisms in or chemical permeation. Additionally, to the physical barriers, clearance of capillaries, cutaneous metabolisms, and skin illness can reduce both permeation and bioavailability. Besides that, the human epidermis is a dynamic tissue, and the dead cells remain on the skin surface for approximately two weeks, leading to malnourishment of the outer epidermis layers. The keratinization or natural renewal of the epidermis is an ongoing process lasting from 28 to 30 days. Keratinization determines the color of the skin, smoothness of its surface, water retention, and the general appearance of the complexion.

Polyethylene and polypropylene synthetic polymer microparticles with a size from $5 \mu \mathrm{m}$ to $1 \mathrm{~mm}$ [86] have been used many times in abrasive cosmetics to achieve mechanical peeling of dead cells and stimulate renewal of the epidermis. Due to their small size, polyethylene and polypropylene microparticles cannot always be captured during the water purification process [88]. In such a manner, they are released into the environment where they are not degraded, such as polystyrenes, polychlorinated biphenyls, or polycyclic aromatic hydrocarbons. Therefore, Cosmetics Europe-the European trade association for the cosmetics and personal care industry-banned from 2020 the use of synthetic solid plastic particles (microbeads) that are nonbiodegradable in the aquatic environment in wash-off products [75]. An innovative atomization process for bio-based biodegradable synthetic polymer has been noticed. Environmentally friendly microparticles shall replace environmentally harmful microplastics in shampoos and other cosmetics. The projects examine the complete process chain from conception of the process to final biodegradability testing after initiation into the water cycle.

Besides that, natural and biodegradable replacements of synthetic polymers have been sought. Polysaccharides' microcarriers and nanocarriers represent approaches to overcome the physical and metabolic barrier to improve the cosmetic effect. Alginates and other biopolymers obtained from sea algae are established among the most versatile biopolymers for cosmetic applications. They are a linear anionic polysaccharide belonging to the group of the copolymers composed of $\alpha$-L-guluronic acid and $\beta$-D-mannuronic acid linked by a glycosidic bond. Alginate salts have been widely used in cosmetic products, as they are generally non-toxic and environmentally friendly [89-91].

The use of polymeric nanoparticles is reported to be of exceptional benefit in many dermatological and ocular applications [92-95], and have been in the core of attention with their outstanding applications in the cosmetology area [3,96-99]. Cosmetical nanoparticles are colloidal active ingredient-loaded particles made from biocompatible compounds, and improve the properties of the active ingredient compared to its bulk material. An active ingredient for cosmetic action based on nanoparticles leads to a special function associated with treating, preventing, keeping the appearance, protecting, or keeping the body in a healthy condition. However, the main objectives for the study of nanotechnologies in the active ingredient/cosmetic delivery area also include the specific targeting, and decreasing toxicity while maintaining beneficial effects, more safety, and biocompatibility [100-103]. 
Nanoparticles prepared from lipids are particularly attractive due to their improved biocompatibility related to the lipid content [104-107]. Evidence suggests that lipid nanoparticles influence the utility of cosmetics since they are safe $[3,108,109]$. Moreover, these nanoparticles may improve the stability of skin-based cosmetics [103].

Modified release nanoparticles may promote skin penetration and depot formation with sustained active ingredient delivery, and their surface functionalization may offer the opportunity for specific targeting into cutaneous and subcutaneous sections. The release of pharmaceutical drugs and other cosmetic ingredients into the skin using polymeric nanoparticles has changed the perspective of the treatment of some cutaneous disorders [110].

\section{Summary and Conclusions}

Natural, semi-synthetic, synthetic, and other modified derivative polymers exhibit different physicochemical and biopharmaceutical properties that can be exploited for use in skin, dental, hair, and nail care. Moreover, they have optimal properties to support active compounds for the cosmetic industry. These valuable characteristics are consistently related, and therefore an accurate polymer characterization is needed to determine which characteristics are more relevant for a specific application. The multi-functional behavior of polymers implies that each one must be characterized not only in terms of its physical-chemical properties but also in terms of biopharmaceutical activity, functional properties, and biological and environmental safety.

Author Contributions: T.F.R.A., M.M., F.B. and M.V.C. contributed for the conceptualization. T.A., D.A.F., C.F.d.S., E.B.S., and P.S. methodology, data analysis and investigation. T.R.F.A., M.M., F.B., T.A. and D.A.F. contributed for the writing - original draft preparation. All authors contributed to writing-review and editing. M.V.C., C.F.d.S., E.B.S. and P.S. contributed for supervision, project administration, resources, and funding acquisition. All authors have read and agreed to the published version of the manuscript.

Funding: This research was funded by Banco do Nordeste (FUNDECI 2017.0016), Coordenação Aperfeiçoamento de Pessoal de Nivel Superior (CAPES) and Fundação de Amparo à Pesquisa do Estado de Sergipe (FAPITEC) (PROCESSO: 88887.159533/2017-00), Conselho Nacional de Desenvolvimento Científico e Tecnológico (CNPq 301964/2019-0, and Chamada CNPq n ${ }^{\circ}$ 01/2019) and by Portuguese Science and Technology Foundation, Ministry of Science and Education (FCT/MEC) through national funds, and co-financed by FEDER, under the project reference UIDB/04469/2020 (strategic fund), co-financed by FEDER, under the Partnership Agreement PT2020.

Conflicts of Interest: The authors declare no conflict of interest.

\section{References}

1. Allied Market Research. Available online: https://www.alliedmarketresearch.com/ (accessed on 12 August 2020).

2. Cosmetics Info. Available online: https://cosmeticsinfo.org/Regulation-in-eu (accessed on 12 August 2020).

3. Dias-Ferreira, J.; Fernandes, A.R.; Soriano, J.L.; Naveros, B.C.; Severino, P.; da Silva, C.F.; Souto, E.B. Chapter 13-Skin rejuvenation: Biopolymers applied to UV sunscreens and sheet masks. In Biopolymer Membranes and Films; de Moraes, M.A., da Silva, C.F., Vieira, R.S., Eds.; Elsevier: Amsterdam, The Netherlands, 2020; pp. 309-330. [CrossRef]

4. Gawade, R.P.; Chinke, S.L.; Alegaonkar, P.S. Chapter 17-Polymers in cosmetics. In Polymer Science and Innovative Applications; AlMaadeed, M.A.A., Ponnamma, D., Carignano, M.A., Eds.; Elsevier: Amsterdam, The Netherlands, 2020; pp. 545-565. [CrossRef]

5. Severino, P.; Fangueiro, J.F.; Chaud, M.V.; Cordeiro, J.; Silva, A.M.; Souto, E.B. Chapter 1-Advances in nanobiomaterials for topical administrations: New galenic and cosmetic formulations. In Nanobiomaterials in Galenic Formulations and Cosmetics; Grumezescu, A.M., Ed.; William Andrew Publishing: Norwich, NY, USA, 2016; pp. 1-23. [CrossRef]

6. Goddard, E.D.; Gruber, J.V. Principles of Polymer Science and Technology in Cosmetics and Personal Care; CRC Press: Boca Raton, FL, USA, 1999.

7. Patil, A.; Sandewicz, R.W. Cosmetic science and polymer chemistry: Perfect together. In Polymers for Personal Care and Cosmetics; American Chemical Society: Washington, DC, USA, 2013; Volume 1148, pp. 13-37.

8. Russo, E.; Villa, C. Poloxamer Hydrogels for Biomedical Applications. Pharmaceutics 2019, 11, 671. [CrossRef] 
9. Nam, H.C.; Park, W.H. Aliphatic Polyester-Based Biodegradable Microbeads for Sustainable Cosmetics. ACS Biomater. Sci. Eng. 2020, 6, 2440-2449. [CrossRef]

10. Smith, J.A.; Murphy, B.J. 24-Soft cell approach to personal care: Hydrophilic active-filled polyurethane delivery systems. In Delivery System Handbook for Personal Care and Cosmetic Products; Rosen, M.R., Ed.; William Andrew Publishing: Norwich, NY, USA, 2005; pp. 513-532. [CrossRef]

11. Johnson, W., Jr.; Heldreth, B.; Bergfeld, W.F.; Belsito, D.V.; Hill, R.A.; Klaassen, C.D.; Liebler, D.C.; Marks, J.G., Jr.; Shank, R.C.; Slaga, T.J.; et al. Safety Assessment of Polyquaternium-22 and Polyquarternium-39 as Used in Cosmetics. Int. J. Toxicol. 2016, 35, 47s-53s. [CrossRef] [PubMed]

12. Tafuro, G.; Costantini, A.; Baratto, G.; Busata, L.; Semenzato, A. Rheological and Textural Characterization of Acrylic Polymer Water Dispersions for Cosmetic Use. Ind. Eng. Chem. Res. 2019, 58, 23549-23558. [CrossRef]

13. Lochhead, R.Y. The Role of Polymers in Cosmetics: Recent Trends; ACS Publications: Washington, DC, USA, 2007.

14. Bakshi, P.S.; Selvakumar, D.; Kadirvelu, K.; Kumar, N.S. Chitosan as an environment friendly-A review on recent modifications and applications. Int. J. Biol. Macromol. 2020, 150, 1072-1083. [CrossRef]

15. Savage, R. Effects of rheology modifiers on the flow curves of idealised and food suspensions. Food Hydrocoll. 2000, 14, 209-215. [CrossRef]

16. Kunz, R.I.; Brancalhão, R.M.; Ribeiro, L.F.; Natali, M.R. Silkworm Sericin: Properties and Biomedical Applications. BioMed Res. Int. 2016, 2016, 8175701. [CrossRef]

17. Padamwar, M.; Pawar, A. Silk sericin and its applications: A review. J. Sci. Ind. Res. 2004, 64, 323-329.

18. Avila Rodríguez, M.I.; Rodríguez Barroso, L.G.; Sánchez, M.L. Collagen: A review on its sources and potential cosmetic applications. J. Cosmet. Dermatol. 2018, 17, 20-26. [CrossRef]

19. Bukhari, S.N.A.; Roswandi, N.L.; Waqas, M.; Habib, H.; Hussain, F.; Khan, S.; Sohail, M.; Ramli, N.A.; Thu, H.E.; Hussain, Z. Hyaluronic acid, a promising skin rejuvenating biomedicine: A review of recent updates and pre-clinical and clinical investigations on cosmetic and nutricosmetic effects. Int. J. Biol. Macromol. 2018, 120, 1682-1695. [CrossRef]

20. Łęska, B.; Messyasz, B.; Schroeder, G. Application of algae biomass and algae extracts in cosmetic formulations. In Algae Biomass: Characteristics and Applications: Towards Algae-Based Products; Chojnacka, K., Wieczorek, P.P., Schroeder, G., Michalak, I., Eds.; Springer International Publishing: Cham, Germany, 2018; pp. 89-101. [CrossRef]

21. Li, Q.; Hu, F.; Zhu, B.; Ni, F.; Yao, Z. Insights into ulvan lyase: Review of source, biochemical characteristics, structure and catalytic mechanism. Crit. Rev. Biotechnol. 2020, 40, 432-441. [CrossRef] [PubMed]

22. Zia, K.M.; Tabasum, S.; Nasif, M.; Sultan, N.; Aslam, N.; Noreen, A.; Zuber, M. A review on synthesis, properties and applications of natural polymer based carrageenan blends and composites. Int. J. Biol. Macromol. 2017, 96, 282-301. [CrossRef]

23. Fruijtier-Pölloth, C. Safety assessment on polyethylene glycols (PEGs) and their derivatives as used in cosmetic products. Toxicology 2005, 214, 1-38. [CrossRef] [PubMed]

24. Poomanee, W.; Khunkitti, W.; Chaiyana, W.; Leelapornpisid, P. Optimization of Mangifera indica L. Kernel Extract-Loaded Nanoemulsions via Response Surface Methodology, Characterization, Stability, and Skin Permeation for Anti-Acne Cosmeceutical Application. Pharmaceutics 2020, 12, 454. [CrossRef] [PubMed]

25. Germershaus, O.; Lühmann, T.; Rybak, J.C.; Ritzer, J.; Meinel, L. Application of natural and semi-synthetic polymers for the delivery of sensitive drugs. Int. Mater. Rev. 2015, 60, 101-131. [CrossRef]

26. Aung, N.N.; Ngawhirunpat, T.; Rojanarata, T.; Patrojanasophon, P.; Opanasopit, P.; Pamornpathomkul, B. HPMC/PVP Dissolving Microneedles: A Promising Delivery Platform to Promote Trans-Epidermal Delivery of Alpha-Arbutin for Skin Lightening. AAPS PharmSciTech 2019, 21, 25. [CrossRef] [PubMed]

27. Klein, M.; Poverenov, E. Natural biopolymer-based hydrogels for use in food and agriculture. J. Sci. Food Agric. 2020, 100, 2337-2347. [CrossRef] [PubMed]

28. Patil, A.; Ferritto, M.S. Polymers for personal care and cosmetics: Overview. In Polymers for Personal Care and Cosmetics; ACS Publications: Washington, DC, USA, 2013; pp. 3-11.

29. Daudt, R.M.; Back, P.I.; Cardozo, N.S.M.; Marczak, L.D.F.; Külkamp-Guerreiro, I.C. Pinhão starch and coat extract as new natural cosmetic ingredients: Topical formulation stability and sensory analysis. Carbohydr. Polym. 2015, 134, 573-580. [CrossRef]

30. Viyoch, J.; Patcharaworakulchai, P.; Songmek, R.; Pimsan, V.; Wittaya-Areekul, S. Formulation and development of a patch containing tamarind fruit extract by using the blended chitosan-starch as a rate-controlling matrix. Int. J. Cosmet. Sci. 2003, 25, 113-125. [CrossRef] 
31. Barbosa, G.P.; Debone, H.S.; Severino, P.; Souto, E.B.; da Silva, C.F. Design and characterization of chitosan/zeolite composite films-Effect of zeolite type and zeolite dose on the film properties. Mater. Sci. Eng. C 2016, 60, 246-254. [CrossRef]

32. Hissae Yassue-Cordeiro, P.; Zandonai, C.H.; Pereira Genesi, B.; Santos Lopes, P.; Sanchez-Lopez, E.; Garcia, M.L.; Camargo Fernandes-Machado, N.R.; Severino, P.; Souto, B.E.; Ferreira da Silva, C. Development of Chitosan/Silver Sulfadiazine/Zeolite Composite Films for Wound Dressing. Pharmaceutics 2019, 11, 535. [CrossRef] [PubMed]

33. Teixeira, M.d.C.; Santini, A.; Souto, E.B. Chapter 8-Delivery of Antimicrobials by Chitosan-Composed Therapeutic Nanostructures. In Nanostructures for Antimicrobial Therapy; Ficai, A., Grumezescu, A.M., Eds.; Elsevier: Amsterdam, The Netherlands, 2017; pp. 203-222. [CrossRef]

34. Andreani, T.; Kiill, C.P.; de Souza, A.L.; Fangueiro, J.F.; Fernandes, L.; Doktorovova, S.; Santos, D.L.; Garcia, M.L.; Gremiao, M.P.; Souto, E.B.; et al. Surface engineering of silica nanoparticles for oral insulin delivery: Characterization and cell toxicity studies. Colloids Surf. B Biointerfaces 2014, 123, 916-923. [CrossRef] [PubMed]

35. Ataide, J.A.; Gerios, E.F.; Cefali, L.C.; Fernandes, A.R.; Teixeira, M.D.C.; Ferreira, N.R.; Tambourgi, E.B.; Jozala, A.F.; Chaud, M.V.; Oliveira-Nascimento, L.; et al. Effect of Polysaccharide Sources on the Physicochemical Properties of Bromelain-Chitosan Nanoparticles. Polymers 2019, 11, 1681. [CrossRef] [PubMed]

36. Jose, S.; Fangueiro, J.F.; Smitha, J.; Cinu, T.A.; Chacko, A.J.; Premaletha, K.; Souto, E.B. Cross-linked chitosan microspheres for oral delivery of insulin: Taguchi design and in vivo testing. Colloids Surf. B Biointerfaces 2012, 92, 175-179. [CrossRef] [PubMed]

37. Severino, P.; da Silva, C.F.; da Silva, M.A.; Santana, M.H.A.; Souto, E.B. Chitosan Cross-Linked Pentasodium Tripolyphosphate Micro/Nanoparticles Produced by Ionotropic Gelation. Sugar Tech 2016, 18, 49-54. [CrossRef]

38. Fonseca-Santos, B.; Chorilli, M. An overview of carboxymethyl derivatives of chitosan: Their use as biomaterials and drug delivery systems. Mater. Sci. Eng. C 2017, 77, 1349-1362. [CrossRef]

39. Rinaudo, M. Chitin and chitosan: Properties and applications. Prog. Polym. Sci. 2006, 31, 603-632. [CrossRef]

40. Liu, M.; Li, X.-Y.; Li, J.-J.; Su, X.-M.; Wu, Z.-Y.; Li, P.-F.; Lei, F.-H.; Tan, X.-C.; Shi, Z.-W. Synthesis of magnetic molecularly imprinted polymers for the selective separation and determination of metronidazole in cosmetic samples. Anal. Bioanal. Chem. 2015, 407, 3875-3880. [CrossRef]

41. Popa, L.; Ghica, M.V.; Dinu-Pîrvu, C.-E. Hydrogels-Smart Materials for Biomedical Applications; IntechOpen: London, UK, 2019.

42. Mohire, N.C.; Yadav, A.V. Chitosan-based polyherbal toothpaste: As novel oral hygiene product. Ind. J. Dent. Res. 2010, 21, 380. [CrossRef]

43. Wassel, M.O.; Khattab, M.A. Antibacterial activity against Streptococcus mutans and inhibition of bacterial induced enamel demineralization of propolis, miswak, and chitosan nanoparticles based dental varnishes. J. Adv. Res. 2017, 8, 387-392. [CrossRef]

44. Aranaz, I.; Acosta, N.; Civera, C.; Elorza, B.; Mingo, J.; Castro, C.; Gandía, M.D.1.L.; Heras Caballero, A. Cosmetics and cosmeceutical applications of chitin, chitosan and their derivatives. Polymers 2018, 10, 213. [CrossRef] [PubMed]

45. Giunchedi, P.; Juliano, C.; Gavini, E.; Cossu, M.; Sorrenti, M. Formulation and in vivo evaluation of chlorhexidine buccal tablets prepared using drug-loaded chitosan microspheres. Eur. J. Pharm. Biopharm. 2002, 53, 233-239. [CrossRef]

46. Mohite, B.V.; Patil, S.V. A novel biomaterial: Bacterial cellulose and its new era applications. Biotechnol. Appl. Biochem. 2014, 61, 101-110. [CrossRef]

47. Iijima, M.; Hatakeyama, T.; Hatakeyama, H. Gel-sol-gel transition of kappa-carrageenan and methylcellulose binary systems studied by differential scanning calorimetry. Thermochim. Acta 2014, 596, 63-69. [CrossRef]

48. Costa, C.; Medronho, B.; Filipe, A.; Mira, I.; Lindman, B.; Edlund, H.; Norgren, M. Emulsion Formation and Stabilization by Biomolecules: The Leading Role of Cellulose. Polymers 2019, 11, 1570. [CrossRef]

49. Kumar-Sarangi, M.; Chandra-Joshi, B.; Ritchie, B. Natural bioenhancers in drug delivery: An overview. P. R. Health Sci. J. 2018, 37, 12-18.

50. Murugesh Babu, K. 7-Spider silks and their applications. In Silk; Murugesh Babu, K., Ed.; Woodhead Publishing: Sawston, UK, 2013; pp. 156-176. [CrossRef] 
51. Murugesh Babu, K. 6-Developments in the processing and applications of silk. In Silk; Murugesh Babu, K., Ed.; Woodhead Publishing: Sawston, UK, 2013; pp. 140-155. [CrossRef]

52. Babu, K.M. Silk: Processing, Properties and Applications; Woodhead Publishing: Sawston, UK, 2018.

53. Numata, K.; Kaplan, D.L. Silk-based delivery systems of bioactive molecules. Adv. Drug Deliv. Rev. 2010, 62, 1497-1508. [CrossRef]

54. Alves, A.L.; Marques, A.L.P.; Martins, E.; Silva, T.H.; Reis, R.L. Cosmetic Potential of Marine Fish Skin Collagen. Cosmetics 2017, 4, 39. [CrossRef]

55. Li, P.-H.; Lu, W.-C.; Chan, Y.-J.; Ko, W.-C.; Jung, C.-C.; Le Huynh, D.T.; Ji, Y.-X. Extraction and characterization of collagen from sea cucumber (Holothuria cinerascens) and its potential application in moisturizing cosmetics. Aquaculture 2020, 515, 734590. [CrossRef]

56. Cindana Mo'o, F.R.; Wilar, G.; Devkota, H.P.; Wathoni, N. Ulvan, a Polysaccharide from Macroalga Ulva sp.: A Review of Chemistry, Biological Activities and Potential for Food and Biomedical Applications. Appl. Sci. 2020, 10, 5488. [CrossRef]

57. Pereira, L. Seaweeds as Source of Bioactive Substances and Skin Care Therapy-Cosmeceuticals, Algotheraphy, and Thalassotherapy. Cosmetics 2018, 5, 68. [CrossRef]

58. Morelli, A.; Massironi, A.; Puppi, D.; Creti, D.; Domingo Martinez, E.; Bonistalli, C.; Fabroni, C.; Morgenni, F.; Chiellini, F. Development of ulvan-based emulsions containing flavour and fragrances for food and cosmetic applications. Flavour Fragr. J. 2019, 34, 411-425. [CrossRef]

59. Hössel, P.; Dieing, R.; Nörenberg, R.; Pfau, A.; Sander, R. Conditioning polymers in today's shampoo formulations-efficacy, mechanism and test methods. Int. J. Cosmet. Sci. 2000, 22, 1-10. [CrossRef] [PubMed]

60. Zhou, Y.; Rigoletto, R.; Koelmel, D.; Zhang, G.; Gillece, T.W.; Foltis, L.; Moore, D.J.; Qu, X.; Sun, C. The effect of various cosmetic pretreatments on protecting hair from thermal damage by hot flat ironing. J. Cosmet. Sci. 2011, 62, 265-282.

61. Velasco, M.; Baby, A.; Inoue, S.; Aktagawa, D.; Dario, M. Formulações de Fixadores/Estilizantes Capilares. Cosmet. Toil. Bras. 2014, 26, 38-43.

62. Abryun, E. Polímeros em produtos de cuidado pessoal. Cosmet. Toil. Bras. 2011, 23, 42-46.

63. Lang, G.; Forestier, S.; Junino, A. Cosmetic Temporary Coloring Compositions Containing Protein Derivatives. U.S. Patent US5192332A, 14 October 1983.

64. Kalopissis, G.; Viout, A. Hair Dyeing Compositions Containing Amphoteric Surface Active Agents. U.S. Patent US3436167A, 15 February 1962.

65. Kalopissis, G. Hair Coloring Compositions Containing Organic Acid Anhydride-Dye Polymers. U.S. Patent US3797994A, 28 January 1966.

66. Gupta, S.; Vyas, S.P. Carbopol/chitosan based $\mathrm{pH}$ triggered in situ gelling system for ocular delivery of timolol maleate. Sci. Pharm. 2010, 78, 959-976. [CrossRef]

67. Flor, J.; Davolos, M.R.; Correa, M.A. Protetores Solares. Quim. Nova 2007, 30, 153-158.

68. Draelos, Z.D. Cosmetics and Dermatologic Problems and Solutions; CRC Press: Boca Raton, FL, USA, 2011.

69. Pereira, I.; Zielinska, A.; Ferreira, N.R.; Silva, A.M.; Souto, E.B. Optimization of linalool-loaded solid lipid nanoparticles using experimental factorial design and long-term stability studies with a new centrifugal sedimentation method. Int. J. Pharm. 2018, 549, 261-270. [CrossRef]

70. Zielinska, A.; Martins-Gomes, C.; Ferreira, N.R.; Silva, A.M.; Nowak, I.; Souto, E.B. Anti-inflammatory and anti-cancer activity of citral: Optimization of citral-loaded solid lipid nanoparticles (SLN) using experimental factorial design and LUMiSizer(R). Int. J. Pharm. 2018, 553, 428-440. [CrossRef]

71. Zielinska, A.; Ferreira, N.R.; Durazzo, A.; Lucarini, M.; Cicero, N.; Mamouni, S.E.; Silva, A.M.; Nowak, I.; Santini, A.; Souto, E.B. Development and Optimization of Alpha-Pinene-Loaded Solid Lipid Nanoparticles (SLN) Using Experimental Factorial Design and Dispersion Analysis. Molecules 2019, 24, 2683. [CrossRef]

72. Zielińska, A.; Ferreira, N.R.; Feliczak-Guzik, A.; Nowak, I.; Souto, E.B. Loading, release profile and accelerated stability assessment of monoterpenes-loaded solid lipid nanoparticles (SLN). Pharm. Dev. Technol. 2020, 25, 832-844. [CrossRef] [PubMed]

73. Thies, C. Microencapsulation. In Encyclopedia of Polymer Science Technology; John Wiley \& Sons, Inc.: Hoboken, NJ, USA, 2004. [CrossRef]

74. Szymański, P.; Markowicz, M.; Mikiciuk-Olasik, E. Adaptation of high-throughput screening in drug discovery-toxicological screening tests. Int. J. Mol. Sci. 2012, 13, 427-452. [CrossRef] [PubMed] 
75. Steiling, W.; Almeida, J.F.; Assaf Vandecasteele, H.; Gilpin, S.; Kawamoto, T.; O’Keeffe, L.; Pappa, G.; Rettinger, K.; Rothe, H.; Bowden, A.M. Principles for the safety evaluation of cosmetic powders. Toxicol. Lett. 2018, 297, 8-18. [CrossRef] [PubMed]

76. Lukic, M.; Jaksic, I.; Krstonosic, V.; Cekic, N.; Savic, S. A combined approach in characterization of an effective w/o hand cream: The influence of emollient on textural, sensorial and in vivo skin performance. Int. J. Cosmet. Sci. 2012, 34, 140-149. [CrossRef]

77. Juliano, C.; Magrini, G.A. Cosmetic Ingredients as Emerging Pollutants of Environmental and Health Concern. A Mini-Review. Cosmetics 2017, 4, 11. [CrossRef]

78. Kim, D.J.; Chang, S.S.; Lee, J. Anti-Aging Potential of Substance P-Based Hydrogel for Human Skin Longevity. Int. J. Mol. Sci. 2019, 20, 4453. [CrossRef]

79. Zheng, S.; Liang, S.; Chen, Y.; Brook, M.A. Hyperbranched Silicone MDTQ Tack Promoters. Molecules 2019, 24, 4133. [CrossRef]

80. Verschoore, M.; Nielson, M. The Rationale of Anti-Aging Cosmetic Ingredients. J. Drugs Dermatol. 2017, 16, s94.

81. Timm, K.; Myant, C.; Nuguid, H.; Spikes, H.; Grunze, M. Investigation of friction and perceived skin feel after application of suspensions of various cosmetic powders. Int. J. Cosmet. Sci. 2012, 34, 458-465. [CrossRef]

82. Gold, M.H.; Sadick, N.S. Optimizing outcomes with polymethylmethacrylate fillers. J. Cosmet. Dermatol. 2018, 17, 298-304. [CrossRef]

83. Kang, S.H.; Moon, S.H.; Rho, B.I.; Youn, S.J.; Kim, H.S. Wedge-shaped polydioxanone threads in a folded configuration ("Solid fillers"): A treatment option for deep static wrinkles on the upper face. J. Cosmet. Derm. 2019, 18, 65-70. [CrossRef] [PubMed]

84. Gedanken, A.; Perkas, N.; Perelshtein, I.; Lipovsky, A. Imparting pharmaceutical applications to the surface of fabrics for wound and skin care by ultrasonic waves. Curr. Med. Chem. 2018, 25, 5739-5754. [CrossRef] [PubMed]

85. Fornes, T.; Paul, D.R. Structure and properties of nanocomposites based on nylon-11 and-12 compared with those based on nylon-6. J. Macromol. 2004, 37, 7698-7709. [CrossRef]

86. Rafiq, R.; Cai, D.; Jin, J.; Song, M. Increasing the toughness of nylon 12 by the incorporation of functionalized graphene. Carbon 2010, 48, 4309-4314. [CrossRef]

87. Moussour, M.; Lavarde, M.; Pensé-Lhéritier, A.M.; Bouton, F. Sensory analysis of cosmetic powders: Personal care ingredients and emulsions. Int. J. Cosmet. Sci. 2017, 39, 83-89. [CrossRef] [PubMed]

88. Cheung, P.K.; Fok, L. Evidence of microbeads from personal care product contaminating the sea. Mar. Pollut. Bull. 2016, 109, 582-585. [CrossRef]

89. Tønnesen, H.H.; Karlsen, J. Alginate in drug delivery systems. Drug Dev. Ind. Pharm. 2002, 28, 621-630. [CrossRef]

90. Tataru, G.; Popa, M.; Costin, D.; Desbrieres, J. Microparticles based on natural and synthetic polymers for ophthalmic applications. J. Biomed. Mater. Res. Part A 2012, 100, 1209-1220. [CrossRef]

91. Severino, P.; da Silva, C.F.; Andrade, L.N.; de Lima Oliveira, D.; Campos, J.; Souto, E.B. Alginate Nanoparticles for Drug Delivery and Targeting. Curr. Pharm. Des. 2019, 25, 1312-1334. [CrossRef]

92. Abrego, G.; Alvarado, H.; Souto, E.B.; Guevara, B.; Bellowa, L.H.; Garduno, M.L.; Garcia, M.L.; Calpena, A.C. Biopharmaceutical profile of hydrogels containing pranoprofen-loaded PLGA nanoparticles for skin administration: In vitro, ex vivo and in vivo characterization. Int. J. Pharm. 2016, 501, 350-361. [CrossRef]

93. Araujo, J.; Vega, E.; Lopes, C.; Egea, M.A.; Garcia, M.L.; Souto, E.B. Effect of polymer viscosity on physicochemical properties and ocular tolerance of FB-loaded PLGA nanospheres. Colloids Surf. B Biointerfaces 2009, 72, 48-56. [CrossRef] [PubMed]

94. Canadas, C.; Alvarado, H.; Calpena, A.C.; Silva, A.M.; Souto, E.B.; Garcia, M.L.; Abrego, G. In vitro, ex vivo and in vivo characterization of PLGA nanoparticles loading pranoprofen for ocular administration. Int. J. Pharm. 2016, 511, 719-727. [CrossRef]

95. Silva, A.M.; Alvarado, H.L.; Abrego, G.; Martins-Gomes, C.; Garduno-Ramirez, M.L.; Garcia, M.L.; Calpena, A.C.; Souto, E.B. In Vitro Cytotoxicity of Oleanolic/Ursolic Acids-Loaded in PLGA Nanoparticles in Different Cell Lines. Pharmaceutics 2019, 11, 362. [CrossRef]

96. Andreani, T.; Dias-Ferreira, J.; Fangueiro, J.F.; Souza, A.L.R.; Kiill, C.P.; Gremião, M.P.D.; García, M.L.; Silva, A.M.; Souto, E.B. Formulating octyl methoxycinnamate in hybrid lipid-silica nanoparticles: An innovative approach for UV skin protection. Heliyon 2020, 6, e03831. [CrossRef] 
97. Barbosa, T.C.; Nascimento, L.E.D.; Bani, C.; Almeida, T.; Nery, M.; Santos, R.S.; Menezes, L.R.O.; Zielinska, A.; Fernandes, A.R.; Cardoso, J.C.; et al. Development, Cytotoxicity and Eye Irritation Profile of a New Sunscreen Formulation Based on Benzophenone-3-poly(epsilon-caprolactone) Nanocapsules. Toxics 2019, 7, 51. [CrossRef]

98. Cefali, L.C.; Ataide, J.A.; Fernandes, A.R.; Sanchez-Lopez, E.; Sousa, I.M.O.; Figueiredo, M.C.; Ruiz, A.; Foglio, M.A.; Mazzola, P.G.; Souto, E.B. Evaluation of In Vitro Solar Protection Factor (SPF), Antioxidant Activity, and Cell Viability of Mixed Vegetable Extracts from Dirmophandra mollis Benth, Ginkgo biloba L., Ruta graveolens L., and Vitis vinifera L. Plants 2019, 8, 453. [CrossRef]

99. Cefali, L.C.; Ataide, J.A.; Fernandes, A.R.; Sousa, I.M.O.; Goncalves, F.; Eberlin, S.; Davila, J.L.; Jozala, A.F.; Chaud, M.V.; Sanchez-Lopez, E.; et al. Flavonoid-Enriched Plant-Extract-Loaded Emulsion: A Novel Phytocosmetic Sunscreen Formulation with Antioxidant Properties. Antioxidants 2019, 8, 443. [CrossRef]

100. Yallapu, M.M.; Jaggi, M.; Chauhan, S.C. Design and engineering of nanogels for cancer treatment. Drug Discov. Today 2011, 16, 457-463. [CrossRef]

101. Dizaj, S.M.; Lotfipour, F.; Barzegar-Jalali, M.; Zarrintan, M.-H.; Adibkia, K. Box-Behnken experimental design for preparation and optimization of ciprofloxacin hydrochloride-loaded $\mathrm{CaCO}_{3}$ nanoparticles. J. Drug Deliv. Sci. Technol. 2015, 29, 125-131. [CrossRef]

102. Dizaj, S.M.; Mennati, A.; Jafari, S.; Khezri, K.; Adibkia, K. Antimicrobial activity of carbon-based nanoparticles. Adv. Pharm. Bull. 2015, 5, 19.

103. Khezri, K.; Saeedi, M.; Dizaj, S.M. Application of nanoparticles in percutaneous delivery of active ingredients in cosmetic preparations. Biomed. Pharmacother. 2018, 106, 1499-1505. [CrossRef] [PubMed]

104. Ataide, J.A.; Gerios, E.F.; Mazzola, P.G.; Souto, E.B. Bromelain-loaded nanoparticles: A comprehensive review of the state of the art. Adv. Colloid Interface Sci. 2018, 254, 48-55. [CrossRef] [PubMed]

105. Souto, E.B.; Muller, R.H. Cosmetic features and applications of lipid nanoparticles (SLN, NLC). Int. J. Cosmet. Sci. 2008, 30, 157-165. [CrossRef]

106. Souto, E.B.; Muller, R.H.; Gohla, S. A novel approach based on lipid nanoparticles (SLN) for topical delivery of alpha-lipoic acid. J. Microencapsul. 2005, 22, 581-592. [CrossRef]

107. Teeranachaideekul, V.; Junyaprasert, V.B.; Souto, E.B.; Muller, R.H. Development of ascorbyl palmitate nanocrystals applying the nanosuspension technology. Int. J. Pharm. 2008, 354, 227-234. [CrossRef]

108. Doktorovova, S.; Kovacevic, A.B.; Garcia, M.L.; Souto, E.B. Preclinical safety of solid lipid nanoparticles and nanostructured lipid carriers: Current evidence from in vitro and in vivo evaluation. Eur. J. Pharm. Biopharm. 2016, 108, 235-252. [CrossRef]

109. Doktorovova, S.; Souto, E.B.; Silva, A.M. Nanotoxicology applied to solid lipid nanoparticles and nanostructured lipid carriers-A systematic review of in vitro data. Eur. J. Pharm. Biopharm. 2014, 87, 1-18. [CrossRef]

110. Gupta, S.; Bansal, R.; Gupta, S.; Jindal, N.; Jindal, A. Nanocarriers and nanoparticles for skin care and dermatological treatments. Ind. Dermatol. Online J. 2013, 4, 267. [CrossRef]

(C) 2020 by the authors. Licensee MDPI, Basel, Switzerland. This article is an open access article distributed under the terms and conditions of the Creative Commons Attribution (CC BY) license (http://creativecommons.org/licenses/by/4.0/). 